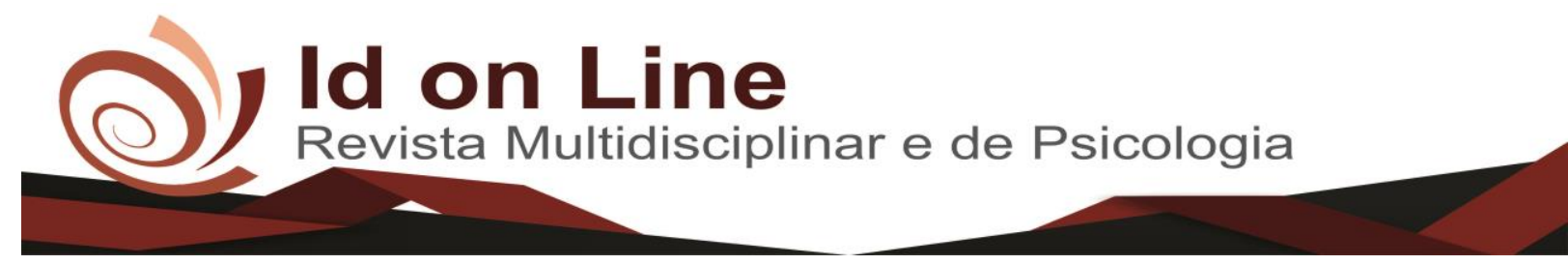

Artigo de Revisão

\title{
A Experiência de Amor dos Pais que tem Filhos com Deficiência no Processo de Aceitação
}

Marilene Alves de Souza ${ }^{1}$; Thércia Lucena Grangeiro Maranhão ${ }^{2}$

\begin{abstract}
Resumo: O presente trabalho retrata o percurso enfrentado pela família que tem um filho com deficiência. É relevante observar e analisar como acontece esse trajeto, a relação pais e filhos, e o processo de aceitação. Objetivando descrever e questionar os sentimentos dos pais em relação aos filhos, os sofrimentos que trazem essa situação nova, e como chegam à aceitação do filho. A pesquisa é bibliográfica. Com resultados e discussões percebe-se que, o nascimento de um filho com deficiência é uma realidade que assola os pais, deixando-os confusos, envoltos em dor e sofrimento. De início os pais são envolvidos pelo sentimento de culpa, transformando-se após em rejeição e vergonha. Precisarão superar juntos com o filho o preconceito da sociedade. É importante ressaltar que tudo se torna fácil de suportar quando os pais são envolvidos pelo nobre e verdadeiro sentimento de aceitação, quando conseguem enxergar a grandeza do filho. Através da aceitação a vida e os caminhos da pessoa com deficiência podem ser significativos e de sucesso.
\end{abstract}

Palavras-Chave: Deficiência. Família. Trajeto. Preconceito. Aceitação.

\section{The Love Experience of Parents with Children with Disabilities in the Acceptance Process}

\begin{abstract}
This work depicts the journey faced by a family that has a child with disabilities. It is relevant to observe and analyze how this happens path, the relationship parents and children, and acceptance process. Aiming to describe and question the feelings of the parents towards their children, the suffering they bring this new situation, and how come the acceptance of the child. The research is literature. With results and discussions it is clear that the birth of a child with disabilities is a reality that plagues parents, leaving them confused, wrapped in pain and suffering. Start parents are involved with guilt, turning on after rejection and shame. Need to overcome together with the son society's prejudice. Importantly, everything becomes easier to bear when parents are involved by the noble and true feeling of acceptance, when they can see the greatness of the child. By accepting the life and ways of the person with disabilities can be significant and successful.
\end{abstract}

Keywords: Disabilities. Family. Path. Prejudice. Acceptance.

\section{Introdução}

A deficiência existe desde os primórdios da historia da humanidade. Antigamente o corpo afetado por uma deficiência era visto como um castigo divino, possessão diabólica ou

\footnotetext{
${ }^{1}$ Psicóloga com curso de Pós- Graduação no método ADI/TIP.

${ }^{2}$ Psicologa CRP 11/05246. Professora da UNILEÃO. Mestra em Ciências da Saúde pela Faculdade de Medicina do ABC. Coordenadora da ABRH-CE Núcleo Cariri. E-mail:therciapsicologa@ gmail.com
} 
força de maus espíritos, tendo assim que ser eliminado do convívio social da comunidade. Com o avanço da ciência e da tecnologia, tem se encontrado as causas da deficiência, que são várias, podendo ser genética, fatores externos, como o uso e abuso de substâncias tóxicas, podem ocorrer antes, durante e após o parto. Seja qual for o motivo, a criança com deficiência merece ser acolhida, acompanhada e cuidada devidamente como merece e necessita.

Algo desejável para alguns cônjuges são os filhos; estes quando chegam trazem uma imensa alegria e satisfação. Mas, quando não vêm perfeitos, como o desejado, é uma grande surpresa e gera vários sentimentos nos pais, confusão e tristeza se misturam, o filho não representa o idealizado, os pais enfrentam assim o luto, de início eles não conseguem compreender o motivo de terem um filho com deficiência e, principalmente como ter os cuidados especializados para com essa criança recém-nascida.

A árdua travessia enfrentada pela família quando é acometida pela chegada de um filho com deficiência, bem como o trajeto percorrido pelos pais no processo de aceitação desse filho resulta numa série de sentimentos onde, com esforço constante terão que enfrentar, assumir e administrar essa nova realidade ( BUSCAGLIA, 1993).

A convivência familiar com o filho com deficiência é estritamente delicada, fazem-se necessários certos cuidados e uma atenção acentuada. São evidentes as dificuldades nessa relação e o apelo por orientações para melhor fazer e conviver. Principalmente a respeito da notícia da deficiência, na maioria das vezes é dada de forma fria e sem uma preparação anterior.

Um turbilhão de sensações desconfortáveis envolve os pais. Sentem dificuldade de vivenciarem esses momentos iniciais, tão sofridos e é imprescindível nessa etapa qualquer forma de apoio. Os pais são assolados por sentimentos de culpa, de rejeição e vergonha. Sentem um grande medo do preconceito da sociedade, e receio com as dificuldades que poderão enfrentar no ambiente escolar. Tudo isso se torna muito evidente e presente.

É relevante observar, descrever e analisar como acontece essa relação pais e filhos, a superação, a aceitação, os comportamentos emitidos, a criação de vínculo, o convívio escolar e social.

Segundo BUSCAGLIA (1993), a chegada de um filho com deficiência no seio de uma família, desponta nos pais uma série de dificuldades e inadequações provenientes de sentimentos de culpa. . Os pais sentem o desejo de fazer algo que possa ajudar seu filho a amenizar essa dor. A criança com deficiência acompanha os conflitos angustiantes de seus pais. 
De acordo com MORAES (2009) criadora do Método ADI- Abordagem Direta do Inconsciente; a criança no ventre materno sente tudo que se passa no ambiente externo e tudo que envolve seus pais e as situações enfrentadas no meio familiar. A criança percebe, acompanha e sente tudo, e aje sobre si mesma, toma decisões livremente sobre seu eu, através de registros que grava no seu inconsciente levando para sua vida.

\footnotetext{
A vida mental e ativa da criança é o inconsciente. Através dele, a criança percebe e registra todos os acontecimentos internos e externos a ela, desde o útero materno. $\mathrm{O}$ que falta, nesta fase à criança são apenas condições neurofisiológicas e físicas para expressar o que sabe. (MORAES, 2009, pg. 73)
}

Os filhos dependem total e absolutamente dos pais, quando bebês; não conseguem fazer nada sozinhos e, tendo uma deficiência, esse cuidado aumenta, torna-se mais acentuado. Toda criança precisa de estimulação em todos os aspectos emocionais, físicos e cognitivos.

É importante na família eliminar do ambiente acusações incoerentes, desfazer os julgamentos e aliviar as tensões, através do diálogo e da compreensão. Isso será propício para o bom convívio e elaboração de papéis, atendendo assim às necessidades individuais, sem danos prejudiciais ou sobrecarga de deveres. Quando isso acontece, a família sente renovada fortaleza, sente-se capaz de buscar sempre o melhor para seu filho e principalmente, de acreditar no potencial do filho, de apoiá-lo e motivá-lo a enfrentar os desafios que o mundo pode oferecer.

Conforme OMOTE (1980), para a pessoa com deficiência, a sua maior aspiração é sentir-se plenamente gente, real e amada. Rótulos, classificações e preconceitos fazem da deficiência um sinônimo de incapacidade e exclusão. Quebrar esses paradigmas que a sociedade coloca é uma missão de cada um de nós. Na medida em que se deseja construir uma humanidade mais justa e igualitária, os protocolos distorcidos se desfazem e dão lugar a certeza de se viver em condições harmoniosas e saudáveis.

Diante disso, este trabalho tem como objetivo refletir como acontece o processo de aceitação do nascimento de um filho com deficiência. Para isso, buscar-se-á descrever os sentimentos que permeiam os pais durante o processo de aceitação do filho com deficiência, questionar a necessidade da assistência profissional no acompanhamento e amparo de famílias que tem filhos com deficiência, compreender a relação familiar com a pessoa com deficiência a partir da superação dos obstáculos para a aceitação do filho. A pesquisa é de carácter bibliográfico, fazendo uso de discurso e análise descritiva. O trabalho é de abordagem qualitativa, fazendo uso de leituras de livros e artigos para construção da pesquisa. 


\section{Percurso Histórico da Deficiência}

A humanidade é marcada pela presença de pessoas com deficiência desde os tempos mais remotos; já se predominava a existência de preconceito em relação aqueles que não correspondiam aos padrões desejados ("normais" e produtivos), sendo considerados como uma ameaça à sociedade. Os sujeitos são classificados de acordo com a sua funcionalidade, o homem é valorizado pela sua força de trabalho. O não funcionamento dentro dos paradigmas da sociedade é sinal de anormalidade na medida que foge do padrão esperado (ARANHA, 2003).

Conforme AMARAL (1994), algumas tribos nômades abandonavam as pessoas com deficiência em lugares inóspitos, expondo-os a um confronto com animais ferozes ou com tribos inimigas. Algumas comunidades jogavam do alto de um morro. Para algumas pessoas, o corpo materializava as forças dos maus espíritos. A deficiência era atribuída principalmente a castigos divinos e, tendo assim que ser eliminada a pessoa do convívio social.

A pessoa com deficiência foi vítima de segregação durante muito tempo e ainda hoje sofre o preconceito da sociedade, alguns manifestam de forma mais velada. É um percurso que se faz e tenta reverter para uma melhor compreensão e aceitação.

Até o século XV crianças com deficiência eram jogadas nos esgotos da Roma Antiga. Na Idade Média, encontravam abrigo nas igrejas, sendo chamadas de bobos da corte. As pessoas com deficiência mental eram vistas como uma possessão diabólica, sendo necessários castigos para uma purificação. Do século XVI ao XIX, as pessoas com deficiência eram encaminhadas para albergues, asilos e conventos, mas não recebiam um tratamento e acompanhamento adequados e dignos. Era mais uma forma de retirar do meio da sociedade, de aprisionar e excluir (AMARAL, 1994).

Percebe-se que a deficiência sempre foi vista e tida como algo negativo e ofensivo, que traz prejuízos e desarrmonias para as pessoas, não permitindo a inclusão do sujeito com deficiência na sociedade, pensa-se em todas as maneiras possíveis de culpar, segregar e extrair das relações sociais.

Para a maioria, ter uma deficiência é sinônimo de incapacidade, improdutividade e inutilidade. Precisa assim ser extinto, pois só traria problema, por não gerar lucro, não ser capaz de produzir nada, apenas sofrimento. Durante muito tempo se pensou assim e, consequentemente, a humanidade se comportou mediante esse pensamento, eliminando as 
pessoas com deficiência. Com o desenvolvimento e avanço das ciências, as causas genéticas das deficiências ou deformações passaram a ser investigadas como um fenômeno natural.

A Organização Mundial da Saúde (OMS,2004), através da Classificação Internacional de Funcionalidade, Incapacidade e Saúde (CIF,2006), conceitua deficiência como "problemas nas funções ou nas estruturas do corpo, como um desvio significativo ou perda".

As principais causas das deficiências são hereditárias ou congênitas, decorrentes de problemas genético, cariótipo e erros do metabolismo como fenilcetonúria, hemoglobina, hipertireoidismo congênito. Doenças como a rubéola, o sarampo, a paralisia infantil e as doenças sexualmente transmissíveis podem ocasionar deformações no feto. O abuso de álcool e drogas, a desnutrição, as famílias de baixa renda que não nutrem devidamente os bebês, a carência de uma boa alimentação pode provocar algo indesejável. A ausência de pré-natal e a falta de um acompanhamento adequado na hora do parto pode provocar sequelas na criança.

As causas das deficiências são inúmeras, algumas podem ser detectadas antes do nascimento. Isso pode favorecer o processo de aceitação desse filho, e mesmo sendo causada durante o parto ou após, é imprescindível o conhecimento e o aprimoramento dessa deficiência para melhor atender as necessidades do seu filho, pois conhecer é uma forma de se aproximar e se apropriar daquilo que compete aos pais. Isso implica um bom desenvolvimento da criança, a superação dos obstáculos, o enfrentamento do preconceito e a inserção na sociedade.

Segundo o Instituto Brasileiro de Geografia e Estatística (IBGE, 2010), no Brasil 24,5 milhões das pessoas têm deficiência. Como estimativa da Organização Mundial de Saúde (OMS, 2004), e a Organização das Nações Unidas (ONU, 2003), o número de pessoas com deficiência em uma determinada cidade ou região é de $10 \%$ da população.

A maioria dessa população mora em área urbanizada e com uma escolaridade incompleta e convívio social restrito; $16,7 \%$ possuem deficiência auditiva e 14,5\% física e mental; $52,46 \%$ dessas pessoas se declaram inativas, $19,12 \%$ são empregados e $12,14 \%$ trabalham por conta própria. É importante ressaltar que existem políticas que defendem os direitos dessas pessoas no trabalho, na saúde e na educação. O Benefício de Prestação Continuada da Assistência Social (BPC) foi instituído pela Constituição Federal de 1988 e regulamentado pela Lei Orgânica de Assistência Social (LOAS), lei 8.742 de 7/12/193. O BPC é um benefício que se integra no Sistema Único de Assistência Social (SUAS), sendo um benefício individual e intransferível, assegurando mensalmente um salário mínimo ao idoso, com sessenta e cinco anos, e à pessoa com deficiência, de qualquer idade, com limitação física, 
mental, intelectual ou sensorial. Atualmente no Brasil 3,6 milhões são beneficiários do BPC, sendo 1,9 milhões pessoas com deficiência. (Ministério da Saúde).

A lei 10.048 , de 8 de novembro de 2000, dá prioridade de atendimento às pessoas com deficiência e a lei 10.098, de 19 de dezembro de 2000, estabelece normas gerais e critérios básicos para a promoção da acessibilidade.A lei 8.213, de 24 de julho de 1991, estabelece a contratação de pessoas com deficiência nas empresas. A lei 8.213/91 também dispõe sobre os planos de Benefícios da Previdência Social e disponibiliza cotas para pessoas com deficiência. Segundo o Ministério da Educação (MEC), entre 2003 e 2011, o número de estudantes com deficiência saltou de 5 mil para 23 mil.

\section{A Expectativa da Chegada de um Filho}

A família é um núcleo da sociedade existente desde o princípio da história da humanidade. O desejo de construir uma família faz parte da maioria das pessoas. Os pares se conhecem, sonham juntos e idealizam toda uma vida unidos, decidem se casar e constituir um lar, realizar sonhos, traçar metas, desenvolver um estilo de vida dentro dos padrões da sociedade (BUSCAGLIA, 2003).

O casal que sente um enorme desejo de ter filhos, de gerar um ser, tem como objetivos perpetuar sua geração e satisfação pessoal. Idealizar o filho é algo normal e completamente natural nos pais; fazer planos, projetos para o bebê, tudo isso traz uma alegria imensa. O filho, quando é planejado gera uma expectativa que motiva e direciona o casal para a sua chegada. Uma ansiedade os invade, proporcionando diversas sensações, de bem-estar e realização, depositando na criança que virá, o afeto que somente as pessoas que têm filhos podem experimentar (DOLTO, 1995).

A vocação de ser pai e mãe está presente principalmente naqueles que formam uma família. Querer um filho, sonhá-lo, projetar nele seus anseios e planos frustrados, educar de acordo com seus costumes, modos e condutas fazem parte de seus propósitos.

De acordo com DOLTO (1995), o ser humano pertence a uma linhagem, faz parte de um mundo transgeracional. Existe dentro do sujeito uma fonte de desejo desde a concepção. Somos movidos por essa força. O nascimento simboliza o desejo de assumir a si mesmo, inscreve-se na concepção. A encarnação no corpo de um sujeito desejante. Pai e mãe esperam 
por esse filho ansiosamente. $\mathrm{O}$ bebê se instala num espaço afetivo triangular.A expectativa do filho começa com esse desejo. Quando os pais percebem que foi gerado, tudo muda a partir desse momento, alegria imensurável, o acompanhamento, os exames, etc., tudo isso implica a esperada criança.

\footnotetext{
A triangulação mãe-pai-filho começa já na concepção. A fecundação já é uma triangulação, e o nascimento, momento consumado de força vital e de desejos, é fruto de um encontro de três desejos: desejo de uma mãe, desejo de um pai e desejo de um sujeito de se encarnar um corpo (DOLTO, 1995, pg. 211).
}

Esses três desejos se misturam, se entrelaçam nesse triangulo de pai, mãe e filho. A força que move a concepção de um novo ser transcende o que é meramente natural e normal. A fecundação vem a ser um movimento de vida, pulsão, que afeta a todos que estão envolvidos nessa atuação. Os sentimentos são diversos, mas a esperança que tudo aconteça com sucesso é evidente. Imaginar que algo possa dar errado é totalmente ameaçador e inaceitável.

\section{A Notícia da Deficiência}

A maneira como os médicos ou enfermeiros dão a notícia da deficiência ou o diagnóstico deveria ser feita através de uma preparação adequada. Os profissionais da saúde, como os psicólogos, médicos e enfermeiros poderiam ajudar nesse momento tão delicado, dando um suporte e apoio técnico, inclusive informações onde buscar auxílio e orientações sobre as deficiências. Existem famílias mais frágeis e vulneráveis, de diferentes níveis de escolaridade, cultura, religião etc.

Receber a notícia da deficiência de seu filho de qualquer forma, pode ser uma agressão ou uma surpresa traumática. É como a morte do filho idealizado (PUPO, 2003). Os pais ao perceberem que sua criança possui limitações que o diferencia dos outros se sentem desnorteados, inconformados, sem nenhuma explicação viável para a realidade presente.

MARCHESE (2002) relata que a maioria dos pais percebe nos profissionais de saúde, descaso e falta de sensibilidade ao darem a notícia da deficiência do recém-nascido. Os serviços de saúde e as redes de apoio poderiam favorecer esse processo de adaptação e aceitação do filho no núcleo familiar e social. Seria bem mais fácil para a família receber o filho com deficiência, 
se o primeiro contato real e físico fosse preparado, orientado e acompanhado por pessoas capacitadas e instruídas para essa finalidade.

Os progenitores estão à espera da criança tão sonhada e desejada. Mas de repente, o filho vem com uma deficiência. Torna-se assim uma situação inesperada, uma realidade nova e assustadora. Essa notícia ao confrontar a idealização, a expectativa e os planejamentos dos pais, gera no seio da família uma desordem, por meio de desconforto e questionamentos.

Para BUSCAGLIA (1993), mesmo depois do impacto inicial, a família precisa se organizar para atender as necessidades de um a criança com deficiência. Isso muda o modo de vida, os valores, os planos e os papéis do sistema familiar.

Quando uma criança nasce, a unidade familiar é modificada em seu status, em sua rede de relacionamentos, assumindo então uma dialética de novos e diferentes papéis (BRADT, 1995). Essa mudança acontece em maior proporção em famílias que têm crianças com deficiência, elas demandam de seus pais uma divisão de tarefas, uma reorganização na estrutura familiar.

\section{Os Sentimentos dos Pais em Relação ao Filho com Deficiência}

Desde o nascimento ao perceber o filho, o mundo dos pais começa a se desestruturar, o bebê tão sonhado não chegou, os projetos, os anseios se desvanecem, terão que mudar ou alterar as atividades, todo um roteiro diferente terá que ser traçado. Uma nova realidade nunca antes imaginada está a sua frente; será preciso buscar forças para conviver com essa situação, de estabelecer uma relação com a criança. Nesse movimento de mudanças os pais experimentam alguns sentimentos fortes como culpa, rejeição e vergonha.

\section{O Sentimento de Culpa}

É bastante comum a presença desses sentimentos, e o mais difícil é saber administrálos. São muitas as interrogações e a procura de respostas diante do acontecido, ou mesmo uma explicação coerente e aceitável. Nessa busca os pais são acometidos por um sentimento de culpa, acreditam que a condição do filho é decorrente de incapacidades genéticas de gerar um 
ser saudável. Os pais clamam por um consolo para suportar tamanha angústia, querem ver se conseguem ter outros filhos normais para provar para si mesmo que são capazes.

\begin{abstract}
Se o casal já tem filho(s) normal(is) é provável que não tenha outros após o afetado, mas se este for primogênito, é provável que tente outros filhos. Há pelo menos duas tendências em jogo com a relação à natalidade subsequente ao filho afetado. Trata-se do temor pela reincidência e a necessidade de comprovar, para si mesmos, que têm potencialidades para gerar crianças saudáveis. Creio que esta segunda tendência tem muito a ver com a necessidade de as mães se isentarem de influência sobre a origem do problema da criança. O filho saudável é uma prova de que não há algo deteriorado na mãe, quando esta percebe-se como responsável pelo comprometimento do mesmo (SILVA: 1988, p.26).
\end{abstract}

Essa tentativa de ter outro filho que seja normal, se no caso o filho com deficiência é primogênito é uma forma de ratificar o erro, a culpa que julga possuir, Independente da maturidade e conhecimento dos pais, o contato com o filho que não seja o perfeito e desejado, traz muita dor, medo e incerteza. Encarar a realidade é um processo difícil e doloroso, por algum tempo ficam envoltos num dilema de culpa e não aceitação.

Assumir a culpa, considerar-se responsável pela condição do filho é algo constrangedor por demais. Querer carregar esse peso irá somente maltratar pais e filhos. São diversos os pensamentos que norteiam suas mentes. Imaginam que poderiam ter evitado de alguma maneira, que deviam ter cuidado melhor da gravidez e nisso a aflição vai se alojando, gerando outras sensações desconfortáveis, (NERI, 2003).

A mãe sente-se mais pressionada, por ter sido ela que carregou em seu ventre a criança. Pensa se não seguiu direito as orientações de seu médico ou se fez algo errado, mesmo que não recorde comportamentos descuidados na sua gestação, algo dentro de si lhe acusa, lhe atormenta, roubando sua tranquilidade.

Há ainda inúmeros outros sentimentos frequentemente encontrados em mães de crianças com deficiências, baixa autoestima da mãe, ás vezes acompanhado do sentimento de culpa, pela falta de cuidado no pré-natal, uso de medicação, tentativas de abortos, drogas, rejeição quanto à concepção, não planejamento da gravidez; busca de respostas até mesmo em teorias de cunho religioso ou místico, como norteadores de seu destino e do filho (OMOTE, 1980, p.24).

O sofrimento é evidente, instaura-se na mãe, chegando a afetar até a sua autoestima e, essa mágoa de si mesma, consequentemente prejudicará também seu bebê. A autopunição é inconfortavelmente desestruturante; trazer o sentimento de culpa é carregar um peso 
escravizador. Para suportar essa dor, a pessoa opta por explicações de diversas fontes, principalmente religiosa; para amenizar a horrível sensação de estranheza no mundo. (CAVALCANTE, 2003).

Cultivar o sentimento de culpa não é bom para manter uma convivência familiar saudável e harmoniosa, é preciso se libertar dessa trave venosa, através de uma boa reflexão individual, aceitando suas mazelas e reconhecendo que a necessidade de superação é urgente, precisa e acessível. Pois o martírio irá apenas prolongar um estado crítico de existência, onde poucos são capazes de compreender e tirar proveito.

As satisfações, disfarçadas, secretas, latentes, manifestam-se por sintomas, a culpa, pode ser equiparada a esses sintomas. Quanto melhor nos esquivamos de nossas pulsões agressivas, mais estas passam ao serviço do superego e mais bem armado fica este para nos torturar. Assim os mais "inocentes" arcam com uma culpa mais pesada (FREUD. 1994, p. 173).

Freud traz a culpa como algo enraizado na pessoa, como sintoma e esta, quando aparece é melhor enfrentá-la. Enquanto brigamos conosco, o superego se fortalece mais nessa acusação. No íntimo de cada sujeito a confusão é processada, difícil de assimilar e interpretar, faz-se necessário uma avaliação do que se tem sido e feito da vida e de suas emoções.

A inocência pode estar envolta da culpa. Nem sempre o individuo é o que se pensa que é, toda a responsabilidade pode ser minimizada, através de uma compreensão lúcida. Quando isso acontece a vida toma uma nova direção, os pais da pessoa com deficiência passam a entender que não vale a pena permanecer na culpa, porque isso não retirará a deficiência, só afetará o seu desenvolvimento.

\section{A Rejeição e a Vergonha}

Um outro sentimento que desponta nos pais de crianças com deficiência é a rejeição e, até mesmo inconscientemente, sem perceber passam a rejeitar seu bebê, não conseguem de início amar verdadeiramente como merecem, por que o filho sonhado, idealizado e desejado não chegou. Ciente dessa perda do bebê perfeito e saudável, os pais sentem-se incapazes de conviver com a novidade inesperada BRADT (1995). 
Conforme MAGALHÃES (1997) essa rejeição está envolvida por um certo desprego que reflete nas atitudes cotidianas no cuidado com a criança em que a atenção é desvinculada, a deficiência ganha um tamanho irreal. Os pais reconhecem aquele ser como filho, entretanto acreditam que algo está faltando, um vazio perscruta dentro de si, o medo os assusta fortemente.

Os pais também sentem vergonha em apresentar à sociedade um ser diferente e estranho, muitas vezes incapaz de mover-se por conta própria, dependendo de outras pessoas para desenvolver atividades simples (BARTALOTT, 2004).

Essas tensões e sentimentos são produzidas devido sintomas já mencionados, os sonhos se desvanecem, o ritmo de vida será transformado por causa do filho. Os conflitos surgem para tentar colocar em ordem o que ainda está bagunçado e fora do lugar, a decisão mais viável é contornar os erros, adequar-se ao momento presente e inegável.

A criança sente a rejeição dos pais, absorve essa energia, é afetada diretamente, sofre por ser o motivo de angústia daqueles que lhe deram a vida. A aversão deixa o ambiente constrangedor e o andamento familiar fica comprometido (SILVA, 1988).

\section{O Processo de Aceitação}

A família encontra-se no limite, não adianta mais sofrer ou camuflar algo tão visível e real; é chegado o momento de assumir as rédeas da situação, de dar um sentido lógico, encontrar meios para sair do ponto de estagnação em que haviam se colocado.

Para REGEN (1993), após enfrentar o sentimento de culpa, de carregar essa dor profunda, de passar pelos caminhos tristemente confusos e aflitos, dos pesares insuportáveis da rejeição, da emissão de comportamentos não compreensíveis, os pais adentram num estágio de reconhecimento, de enfrentamento de si mesmo, abandonam o disfarce e se dispõem a admitir suas franquezas. Entram num processo de descobertas, de instigações e nova organização de suas vidas e reestruturação familiar. Essa etapa positiva é valorosa para todos que constituem o lar,especialmente o bebê com deficiência.

Os pais vão à procura de ajuda, sentem-se fragilizados e ao mesmo tempo receptivos aos auxílios externos, pois não se julgam mais os últimos, os castigados e sim seres como tantos outros. Encontram praticamente uma comunidade semelhante, passam a cultivar e manter um grande vínculo fraterno de relacionamento e troca de experiência, isso quando conhece outras 
famílias que tem pessoas com deficiência em casa, percebem como é gratificante e enriquecedor. Inicia-se uma convivência mais alegre e sadia. Saem do patamar de desconforto e isolamento para um aliviante e compreensível.

A família da pessoa com deficiência, principalmente os pais, são os protagonistas que mais terão de atuar, aprender e ensinar ao seu filho a amar, viver e ser feliz da maneira que sabem e podem, mediante as condições possíveis. De acordo com MAGALHÃES (1997), a liberdade e o direito de viver dignamente são para todos, inclusive para as pessoas com deficiência. Quando isso se torna perceptível, os pais sentem-se agraciados de terem em suas vidas um ser tão singular e afetuoso. É possível a realização de diversas atividades educacionais, recreativas e sociais. Nenhuma pessoa com deficiência deverá ser submetida, em sua residência a tratamento diferencial, deve ser inserido no meio social, integrado como membro vivo e participante, capaz de dar sua parcela de contribuição para a comunidade.

É evidente no filho com deficiência que a maior aspiração de sua vida é sentir-se plenamente gente, real, amado, reconhecidos em todos os seus aspectos emocionais, físicos e cognitivos. Como todo ser humano ele tem capacidade de se realizar, de ser feliz, de doar, de receber, de ensinar e aprender. No seu coração não existe limitações ou deficiências, lá predomina muito amor, inimaginável onde muitos se surpreendem com sua imensa grandeza de ser e se manifestar. Os pais que se permitem conhecer seus filhos, nos mínimos detalhes retiram lições de vida, crescem e amadurecem admiravelmente.

Os parentes e amigos precisam também dar apoio à família da pessoa com deficiência, auxiliando em algumas dificuldades aparentes, orientando na procura de instituições para favorecer a integração social, e destruir as barreiras do preconceito infelizmente ainda predominante.

Conforme MELO (2008), com a ajuda e incentivo, os pais conseguem acreditar que seu filho tem todas as condições de construir sua personalidade e manter relações, de sentir e conviver com variados sentimentos e que seu corpo pode até apresentar alguma deformação, mas a sua alma e o seu coração são perfeitos, inteiros e belos.

\footnotetext{
Mãe, eu estou aqui. Sociedade, eu sou gente. Gente com alma que vibra, com alma que chora, com o sentimento que é capaz de compreender aqueles e a todos que não nos compreendem. Brasil, eu sou também um pedaço de ti, eu sou estrela que brilha, eu sou terra quente do Nordeste, eu sou o frio do sul, eu sou rebuliço das cidades, a vastidão da terra, a expressão cândida do amor (RIBEIRO, 1981, p.51).
} 
A pessoa com deficiência é um ser como qualquer outro; apenas com alguma deficiência visível, onde os ditos "normais" com sua atitude preconceituosa revelam suas deficiências ocultas. Em compensação, se encontram pessoas que enxergam com carinho, atenção e profundo respeito as pessoas com deficiência; que reconhecem suas habilidades e competências, principalmente a grandeza imensurável de sentir e amar, o desejo de viver plenamente, de compartilhar suas vidas com aqueles em que deposita confiança e segurança.

O papel de família é oferecer um campo de treinamento seguro, onde as crianças possam aprender a serem mais humanas, a amar, a formar sua personalidade única, a desenvolver auto imagem, e a relacionar-se com a sociedade mais imutável, da qual e para qual nascem (BUSCAGLIA, 1993, p.41).

A necessidade de pertencer e estabelecer vínculos é uma propensão natural dos seres humanos, todos carecem de um envolvimento verdadeiro e significativo. Ter a certeza de ter pessoas que estão ao seu lado, que se dispõem a contribuir para um bom desenvolvimento emocional, cognitivo e social, que lhe transmitem segurança, paz e conforto, é essencialmente necessário para a pessoa com deficiência. Mais do que ninguém, é merecedor de atenção, de reconhecimento de sua dignidade humana (CAVALCANTE, 2003).

Deficiência não é sinónimo de incapacidade. Cada vez mais, as pessoas com deficiência emergem como protagonistas de suas vidas e destinos, deixando de ser meros objetos de ações de assistência individual e social. A pessoa com deficiência é possuidora de dons únicos e apreciáveis, capaz de impressionar qualquer indivíduo, basta recordar quantos poetas, músicos, escritores e pintores ao longo da história, tinham alguma deficiência e se tornaram famosos e célebres da humanidade a exemplo de Betowen, Aleijadinho etc.

Numa sociedade que, paradoxalmente, tanto defende, quanto ameaça os direitos humanos, falta acolhida às pessoas com deficiência e aos seus familiares. Muitos contra valores implementados na sociedade repercutem na exclusão e, é preciso ultrapassar essa barreira, adquirindo uma posição de manifestação solidária e fraterna à família e ao filho com deficiência (PUPO,2003).

Enquanto membro constituinte de uma sociedade, somos gente assim, como a pessoa com deficiência, dignos de total e absoluta consideração, sem distinção, nem rotulação. $\mathrm{O}$ respeito deve ser estabelecido e expressado com amor sincero e delicado. A conscientização deve partir de cada um, o tratamento visto e praticado se torna um forte exemplo para os que ainda precisam reconhecer e valorizar a deficiência sem receios, eliminando toda 
marginalização classificatória de rejeição. Esse é um grande desafio da sociedade moderna para se tornar mais igualitária.

Como marginalizados, "seres fora de" ou à margem de, a solução para eles estaria em que fossem integrados, incorporados, à sociedade sadia de onde um dia partiriam, renunciando como trânsfugas a uma vida feliz... (FREIRE, 1992, p. 61).

A recusa em dar outra direção ao paradigma que sustenta um perfil social estereotipado, classificando as pessoas de acordo com suas condições financeiras, culturais e físicas, implica em seleções desumanas, onde pessoas dotadas de sentimentos, inteligência e capacidade de inferir no meio social são rejeitadas, expulsas das regalias que os grupos sociais podem oferecer.

\section{Considerações Finais}

A construção desse trabalho relatou os desafios na família marcada pela presença da deficiência em um filho. Num primeiro momento, a experiência é penosa e desgastante, mas com o conhecimento, enfrentamento e aceitação o quadro é revertido em compreensão e dedicação para com o filho.

O sofrimento da família é resultado da pouca informação sobre a deficiência, da falta de preparação, bem como da dificuldade de entender o porquê de acontecer com eles. Essa situação é nova e totalmente estranha, os pais desejam o tempo todo uma explicação plausível e forças para enfrentar a realidade e aceitar o filho.

Os sentimentos dos pais em relação aos filhos são de culpa, rejeição e vergonha. É natural a presença desses sentimentos. Em alguns acontece de forma mais intensa e demora mais tempo para administrar, noutros em proporção menor. Pois o filho que têm é como um substituto do filho idealizado. Os pais passam então pelo luto do filho sonhado para aceitar o filho com deficiência.

O que os psicólogos poderiam fazer para auxiliar no processo de aceitação e inclusão a família e a pessoa com deficiência? Pois são influenciados pela sociedade e na medida em que preconceitos são vencidos e novos conceitos estabelecidos, todos são beneficiados pelo que o respeito e a solidariedade podem proporcionar. 
O fomento dessa interação, juntamente com a disponibilidade doativa de todos que convivem com a pessoa com deficiência, reflete para a humanidade a certeza de ancorar na confiança das capacidades da diversidade. Todos são aptos a contribuir, para a formação de um mundo mais íntegro e fraterno.

\section{Referências}

AMARAL, L. A. Pensar a Diferença/Deficiência. Brasília: Editora Corde, 1994.

ARANHA, M. S. F. Trabalho e Emprego. Brasília: CORDE, 2003.

BARTALOTTI, C. C. Nenhum de nós é tão esperto como todos nós. São Paulo: PUC/SP, 2004.

BRADT, J. O. Tornando-se pais: Famílias com filhos pequenos. In: CARTER, B.; MCGOLDRICK, M. As mudanças do ciclo de vida familiar: uma estrutura para a terapia familiar. 2 ed. Porto Alegre: Artmed, 1995.

BUSCAGLIA, L. F. Os deficientes e seus pais. Rio de Janeiro: Editora Record, 1993.

CAVALCANTE, F. Pessoas muito especiais: a construção social do portador de deficiência e a reinvenção da família. Rio de Janeiro: Editora Fiocruz, 2003.

CONGRESSO DA FEDERAÇÃO NACIONAL DAS APAES. Belo Horizonte: Federação Nacional das APAEs, 1981.

FREIRE, P. Pedagogia do Oprimido. 20 ed. Rio de Janeiro: Paz e terra, 1996.

FREUD, et al. Introdução às obras de Freud, Ferenczi, Groddeck, Klein, Klein, Winnicott, Dolto, Lacan/ sob a orientação de J.-D. Nasio, com as contribuições de A.-M. Arcangioli; tradução, Vera Ribeiro; revisão, Marcos Comaru. Rio de Janeiro: Editora Jorge Zahar, 1995.

OCTAVE; MANNONI. Freud: uma biografia ilustrada. Rio de Janeiro: Editora: Jorge Zahar, 1994.

NASIO, Juan David. Introdução ás obras de Freud, Ferenczi, groddeck, Klein, Winnicott, Dolto, Lacan . Rio de Janeiro: Jorge Zahar, 1995.

GIL, A. C. Como elaborar projeto de pesquisar. 4 ed. São Paulo: Atlas, 2002.

LIPP, M. N. (Org.). Sexo para deficientes mentais: sexo e excepcional dependentes e nãodependentes. 4 ed. São Paulo: Cortez, 1998. 
MAGAlHãeS, A. C. Família e Profissionais: rumo à parceria. Brasília: FNA, 1997.

MARCHESE, D. M. A. O Nascimento do Cidadão Diferente: Prognóstico ou Julgamento?. São Paulo: Universidade Presbiteriana Mackenzie, 2002.

MORAES, R. J. As Chaves do Inconsciente. 25 ed. Petrópolis. Rio de Janeiro Vozes, 2009. NERI, M. Retratos da deficiência no Brasil. Rio de Janeiro: FGV/IBRE, 2003.

OMOTE, S. Reações de mães de deficientes mentais ao reconhecimento da condição dos filhos afetados: um estudo psicológico. São Paulo, 1980.

PUPO FILHO, R. A. O momento da descoberta. In: SOUZA, A. M. C. A criança especial: temas médicos, educativos e sociais. São Paulo: Roca; 2003.

REGEN, M. Mães e filhos especiais: relato de experiência com grupos de mães de crianças com deficiência. Brasília: CORDE, 1993.

RODRIGUES, S. Direito Civil. 32 ed. São Paulo: Saraiva, 2002.

SILVA, S. F. Experiências e necessidades de mães após o diagnóstico de deficiência física e mental de seu filho. São Carlo: Universidade Federal de São Carlos, 1998.

Sites:

ASSOCIAÇÃO DE PAIS E AMIGOS DE EXCEPCIONAIS - www.apaebrasil.org.br

COORDENARIA NACIONAL PARA A INTEGRAÇÃO DA PESSOA PORTADORA DE DEFICIÊNCIA - CORDE- www.mj.gov.br/sedh/ct/corde/dpdh/corde

INSTITUTO BRASILEIRO DE GEOGRAFIA E ESTATÍSTICA (IBGE), 24 de junho de 2010 - www.ibge.gov.br

MINISTÉRIO DA SAÚDE. Portal dos Serviços de Saúde do Governo Federal portalsaude.saude.gov.br/portalsaude/index.html noticias.terra.com.br/brasil/ 17 de outubro de 2003 . Disponível em > www.acessobrasil.org.br.2002.

Como citar este artigo (Formato ABNT):

SOUZA, Marilene Alves de; MARANHÃO, Thércia Lucena Grangeiro. A Experiência de Amor dos Pais que tem Filhos com Deficiência no Processo de Aceitação. Id on Line Rev.Mult. Psic., 2018, vol.12, n.42, p. 187-202. ISSN: 1981-1179.

Recebido: 24/08/2018;

Aceito: $27 / 08 / 2018$ 